\title{
1. Introduction: ministerial administrations and policy change in climate policy
}

The notion of climate change entered the political debate in the 1980s. However, despite a political debate that stretches over almost four decades, in many countries the definition of the problem of climate change is still as contested, as are the solutions to this problem. The rise of the science on anthropogenic climate change has been accompanied by the rise of climate skepticism, the 'organized climate change denial' (Dunlap and McCright 2011; Dunlap 2013). Climate policy seeks a transformation of lifestyles and infrastructures that permeates all spheres of life (WBGU 2011). It seeks to alter our ways of extracting and consuming energy and resources. This encompasses change in our ways of doing, thinking and organizing across the domains of energy, economy, mobility, housing and urban development, research and education, agriculture and finance. Such transformative change fundamentally questions the distribution of wealth and power in human society (Connelly et al. 2012). It challenges society to reflect upon and redefine its values, beliefs and interests. This raises the question of how policy change is possible in such a contested context. And what is the role of social science in this quest? This book is about policy change. It shows how novel ideas enter domestic discourses and institutions and are deliberated within them.

\subsection{CLIMATE POLICY ANALYSIS: MOVING BEYOND THE POLITICS/ADMINISTRATION DICHOTOMY}

There is no doubt that climate policy has received ample interest by researchers (Fahey and Pralle 2016). While climate policy analysis emerged as a subfield of environmental policy analysis, it has evolved into a field of its own. Existing scholarship has analyzed different actors engaged in climate policy, the science-policy interface, processes of policy diffusion and policy convergence, and the policy instruments employed in climate policy. It has studied the emergence and effectiveness of environmental advocacy groups in influencing political decision-making (Boasson 2015; Connelly et al. 2012, 
pp. 94-136; Rootes 2003). It has shown how environmental movements developed out of a critique of the status quo to promote alternative, nonmaterialist values. In a similar vein, scholarship has examined the development trajectories of green parties and their role in policy processes (Connelly et al. 2012, pp. 108-21; Frankland et al. 2016; Knill et al. 2010; Müller-Rommel and Poguntke 2012).

The scientific findings on anthropogenic climate change were at the root of the political debate on climate policy. Thus, science and politics have been interwoven in climate policy in a peculiar manner. Notwithstanding the different systems of logic underlying science and politics, studies point to the scientification of politics as well as the politicization of science (Fischer 2000; Haas 2004; Nilsson 2006; Sarewitz 2011; Weingart 1983). Reflecting the dynamics of international exchange and emulation between national contexts, policy diffusion studies have impacted climate policy analysis, resulting in extensive research on both policy diffusion and policy convergence processes in a range of different national contexts (Albrecht and Arts 2005; Arts et al. 2008; Busch and Jörgens 2005a; Busch and Jörgens 2005b; Holzinger et al. 2007; Jörgens et al. 2013).

In the search for solutions, scholars have analyzed the creation and effectiveness of policy instruments (Jordan et al. 2003; Wurzel et al. 2013). These encompass regulatory, economic, information, voluntary and institutional instruments, addressing the organization of government (Connelly et al. 2012, pp. 178-200). The exploration of the instruments on the organization of government is closely linked to the literature on environmental policy integration (Jacob et al. 2008; Jordan and Lenschow 2008; Jordan and Lenschow 2010; Lafferty and Hovden 2003; Lenschow 2002; Schout and Jordan 2008). This field of study addresses a general problem posed by the specialization of ministries or departments: If specialization hinders the exchange of knowledge and collaborative learning between ministries and departments, policies can become compartmentalized and fragmented (Connelly et al. 2012; Haas 2004, p. 587; Müller 2002, p. 69). This makes it particularly challenging to address horizontal policies like climate policy that cross the boundaries of several policy domains. The debate on environmental policy integration recently gave rise to a debate on climate policy integration (Adelle and Russel 2013).

Given this wide range of subjects covered by climate policy analysis, why conduct yet another study of climate policy? Scholars argue that national governments as 'important - indeed, central - players in environmental politics and policy' (Fahey and Pralle 2016, p. 39) remain a black box in climate policy analysis. This applies even more to public administrations. Consequently, '[i]t is time to bring the state back in' (Purdon 2015, p. 6). The study of institutions in climate policy often focuses more on macro-institutional 
choices such as unitary versus federal systems or majority versus consensus democracies (Connelly et al. 2012, pp. 315-23). However, little is known about micro-institutional choices such as public administrations and their internal structures, cultures and practices (Dimitrov et al. 2006, p. 15; Jacob and Jörgens 2011, p. 26).

In environmental policy analysis, public administrations have received interest in the literature on institutional instruments addressing the organization of government and on environmental policy integration. This literature acknowledges that 'the architecture of government matters' for the formulation and implementation of policies, even if it is seen to be only one of many factors influencing public policy (Connelly et al. 2012; Fleischer and Hustedt 2012; Müller 1995; Müller 2002). Studies on the causes and consequences of institutional change have shown that the emergence of environmental ministries and agencies has created more continuity and given the environment a voice within the government (Connelly et al. 2012).

In a similar vein, the role of public administrations received new attention in the study of international and European Union (EU) environmental policy (Bauer 2006; Bauer, Knill and Eckhard 2017; Biermann and Siebenhüner 2009; Busch 2009). These scholars contend that the study of public administrations remains a research gap in international relations theory. They argue that the role of public administrations should not be downplayed to that of purely neutral, technocratic actors. On the contrary, they shape policy debates with their own beliefs and values (Bauer 2006; Benner et al. 2009). Thus, the authors call for a dialogue between international relations theory and the scholarship on public administrations (Bauer et al. 2009; Bauer, Knill and Eckhard 2017). The same holds for the supra-national organization of the EU. More recently, scholars have begun to analyze the role of the EU Commission in climate policy (Dreger 2014; Hustedt and Seyfried 2016). Moreover, researchers have examined the link between the Europeanization of national policy and the nationalization of EU policy and the role of national ministerial administrations therein. They have explored how EU policy shapes domestic policy-making and, conversely, how national ministries influence EU policy-making (Jordan 2003; Jordan and Schout 2006; Skjærseth et al. 2016).

These calls for exploring the role of public administrations in environmental and climate policy raise questions about the nature of politics and public administrations. The assumption of a dichotomy between the two has long been called into question, described as 'a convenient fiction rather than a description of any reality' (Campbell and Peters 1988, p. 82). As the formulation of policy relies on specialization and expertise, public officials become important mediators by translating the political priorities of politicians into the technical language of legislation (Page 2003, p. 652; Page and 
Jenkins 2005, p. 10). They are pivotal in the process of defining problems and developing policy solutions. Therefore, as public officials sketch out the details of a policy, they acquire substantial discretion over the policy process (Bauer, Eckhard, Ege and Knill 2017, pp. 3-5; Page 2003; Page and Jenkins 2005 , p. 2; Page 2012). This suggests that '[m] aking policy is a collaboration between the two parts of the executive' (Page and Jenkins 2005, p. 183). It implies that the nature of ministerial administrations is inherently political, combining technocratic-administrative and political components. They are the locus where societal conflicts are deliberated and where the balance between particular interests and the common good is negotiated. Hence, ministerial administrations are not one unified entity, but 'many organizations in one' (cf. Dreger 2014, p. 4).

While hierarchy and expertise are key characteristics of ministerial administrations, the relationship between the two is inherently marked by tensions. The expertise of public officials 'gives them power over their inexpert masters' (Page and Jenkins 2005, p. 10). This poses the question of how politicians can effectively control public officials and how democracy can be possible in a bureaucracy (Bauer, Eckhard, Ege and Knill 2017, p. 5; Page 2003, p. 673; Page and Jenkins 2005; Schnapp 2004, pp. 52-67; Weber 1921 [1972], pp. 128-30, 854-5). Politicians do exercise control through their final approval of policies (Page 2003, p. 673; Page and Jenkins 2005, p. 184). However, this is not only a question of how public officials can elude the control of political masters, but also of how public administration can be shielded from political usurpation (Campbell and Peters 1988, p. 80). The ensuing tensions attest to everyday challenges in policy-making, as politicians and public officials are compelled to balance out the hierarchical superiority of the one with the expertise-driven power of the other (Page and Jenkins 2005, p. 13; Schnapp 2004, pp. 62-7).

Against this backdrop, this book argues that policy change will be better understood by studying the actors formulating these policies, namely ministerial administrations. It captures, not merely party politics and interest group politics, but the departmental politics of policy change. The book therefore focuses on the coordinative discourses within governmental institutions. These are the discourses among the actors participating in the construction of a policy, which stand in contrast to the communicative discourses through which politicians communicate and justify their policies vis-à-vis the public (Schmidt 2002, pp. 231 et seq.; Schmidt 2008, pp. 310 et seq.).

In shedding light on the inner workings of ministerial administrations, the book seeks to answer the following overarching research question:

- Why are policies changed or continued in climate policy? 
This is underpinned by the following sub-questions:

- How do ministerial administrations shape policy formulation in climate policy?

- How do coordinative discourses on the formulation of policies evolve? How are they informed by particular identities, policy frames and institutional contexts?

- How can ideas be reinterpreted, values be reframed and interests be redefined?

As policy change is situated at the crossroads of political institutions, administrative institutions and policies, the book seeks to combine the perspectives of public policy and public administration. Building on discursive neoinstitutionalism, it introduces a conceptual framework that integrates ideas, discourses and institutions. The comparative analysis covers a wide range of EU countries, including both Western European and Central Eastern European (CEE) countries, large and small states. By doing so, it seeks to shed light on an aspect of climate policy that has remained under-explored so far, namely energy consumption. The details of this approach are outlined in the following.

\subsection{THE CONTRIBUTION OF THE STUDY: IDEAS, DISCOURSES AND INSTITUTIONS}

Neo-institutionalism is a diverse body of literature. It is not one, but many neoinstitutionalisms. These accounts are most often differentiated into rational choice (RI), historical (HI), sociological (SI), and more recently discursive neo-institutionalism (DI). Each of them follows its own understanding of institutions. RI defines institutions as incentive structures (a logic of consequentiality), HI as self-enforcing historical paths (a logic of path-dependency), SI as social entities framed by cultural norms (a logic of appropriateness), and DI as structural contexts of the discourse through which political ideas are generated and reinterpreted (a logic of interpretation and communication) (Peters 2005; Schmidt 2009a).

In parallel to neo-institutionalism, the 'argumentative turn' emerged (Fischer and Forester 1993). This is a turn to ideas which introduces a constructivist perspective in policy analysis and public administration. ${ }^{1}$ It defines social reality not as objectively given, but as intersubjectively constructed. It argues that 'facts do not speak for themselves', but acquire meaning only through interpretation (Fischer 2003b, p. 13; Hajer 1995). Therefore, the perceptions and interpretations of actors become the very subject of analysis. 
The argumentative turn has profoundly challenged the methodological underpinnings of social science research, shifting them from positivism to constructivism. This constructivist ontology is accompanied by an interpretive epistemology. It is important to note that, while constructivism and interpretivism address many of the same questions, they come from different directions (Hay 2016, pp. 110-11). Constructivism is grounded in ontology, exploring the nature of social reality. It studies institutions as constituting the social world. Interpretivism is grounded in epistemology, enquiring how we can know something about social reality. It emphasizes the 'perspectival and interpretive character of all social understanding' (ibid. p. 110).

Introducing the turn to ideas into neo-institutionalism, DI criticizes that the conceptions of ideas proposed by RI, HI and SI remain rather static. RI, HI and SI see ideas as static ideational structures that frame institutional incentives, historical paths or persistent cultures (Peters 2005, p. 115; Schmidt 2009a). By contrast, DI portrays ideas as dynamic and amenable to change (Campbell 2004, p. 91; Schmidt 2009a, pp. 134-5). DI seeks to illustrate how ideas can redefine interests, reshape historical paths and recreate cultures. Hence, it argues that ideas have a power of their own.

However, DI emphasizes that the meaning of ideas as 'text' can only be understood within their 'context' (Hay 2011; Schmidt 2002, pp. 240 et seq.; Schmidt 2008, p. 314; Schmidt 2010b, pp. 59-60). Therefore, it seeks to integrate ideas, discourses and institutions in the exploration of policy change. With the study of ideas, discourses and institutions, this book builds on DI and the notion of the institutional context this proposes. Focusing on ministerial administrations implies a shift from macro-institutional choices to microinstitutional choices and studying the features of the political-administrative institutions in question. Moving beyond an understanding of 'simple polities' and 'compound polities' (Schmidt 2002, pp. 240 et seq.; Schmidt 2008, pp. 312 et seq.), the study seeks to develop a more fine-grained understanding of these micro-institutions that incorporates their formal and informal elements. This perspective can offer both analytical and empirical insights on ministerial administrations and policy change.

\subsection{THE METHODOLOGY OF THE STUDY: WESTERN EUROPEAN AND CENTRAL EASTERN EUROPEAN COUNTRIES, LARGE AND SMALL STATES}

The turn to ideas and likewise DI propose a shift towards a constructivist ontology and an interpretive epistemology. This suggests the need to clarify what they are and how they differ from a positivist ontology and epistemology. By comparing the positivist and the interpretive research paradigm I do 
not mean to argue that one of them is superior. Each pertains to specific research questions. By acknowledging both I mean to endorse methodological pluralism and to explicate the methodological underpinnings of my own research.

\section{The Positivist and the Interpretive Research Paradigm}

In a critique of the positivist research paradigm, the 'interpretive paradigm' arose to endorse 'the centrality of meaning in human life' (Yanow and Schwartz-Shea 2006, p. xii). The positivist ontology is based upon the belief that social reality is given and objective. By contrast, the constructivist ontology conceives of the social world as socially constructed (see for example Bevir and Rhodes 2016; Fischer 2003a; Fischer 2007; Schwartz-Shea and Yanow 2012; Wagenaar 2011; Yanow 2006b).

These ontological differences entail disparity in the epistemology of positivist and interpretive research. Suggesting that objective facts exist, positivism believes in the 'fact-value dichotomy' (Bernstein 1976, p. 230; Fischer 2003b, p. 122). The researcher is seen as a neutral observer who describes and explains the social world. Unlike positivism, interpretivism argues that "the "brute" data of the social and policy sciences are not hardwired into social reality, but require interpretation to make them "visible" at all' (Wagenaar 2011, p. 16). It assumes that such a world can be explored only through interpretation. Therefore, it sets out to 'challeng[e] the myth of value neutrality' (Hawkesworth 2006, p. 48), arguing that treating facts and values as ontologically distinct is flawed. Instead, it presumes that all observation is theory- and value-laden. These theoretical perspectives and normative values are what the social world is constructed by and, therefore, the core subject of interpretive research.

The shift from positivism to interpretivism also challenges the conception of causality. While positivist research follows a logic of explanation and searches for causal laws and generalizability, interpretive research follows a logic of understanding and emphasizes contextuality and 'thick description' (Geertz 1973). This is associated with a 'constitutive causality' that explores what constitutes human action (Schwartz-Shea 2006, p. 109; Schwartz-Shea and Yanow 2012, pp. 51-3; Yanow 2014, p. 149). It argues that the choices of actors can only be understood by elucidating the reasons that informed them (Bevir and Rhodes 2016, p. 5). Therefore, the conclusions of interpretive research can be seen more as an argument, displaying multiple interpretive judgements and drawing comparative lessons, than as inductive or deductive proof (Bevir et al. 2003a, p. 198; Fischer 2003a, p. 222; Yanow 2006b, p. 17).

This alters the research process. In positivist research, concepts and propositions on the causal relationships between factors are formulated a priori to be subsequently examined in the field. While interpretive research is also 
Table 1.1 The positivist and the interpretive research paradigm

\begin{tabular}{lll}
\hline The positivist research paradigm & $\begin{array}{l}\text { The interpretive research } \\
\text { paradigm }\end{array}$ \\
\hline Ontology & $\begin{array}{l}\text { The social world as objectively } \\
\text { given }\end{array}$ & $\begin{array}{l}\text { The social world as socially } \\
\text { The 'fact-value dichotomy' } \\
\text { (Bernstein 1976, p. 230; Fischer }\end{array}$ \\
2003b, p. 122) & $\begin{array}{l}\text { All knowledge is theory- and } \\
\text { value-laden }\end{array}$ \\
Epistemology & $\begin{array}{l}\text { A logic of explanation } \\
\text { (Erklären) }\end{array}$ & $\begin{array}{l}\text { A logic of understanding } \\
\text { (Verstehen) } \\
\text { The search for generalizability }\end{array}$ \\
& $\begin{array}{l}\text { The search fontextuality and } \\
\text { thick description' (Geertz 1973) }\end{array}$ \\
Methodology & $\begin{array}{l}\text { Qualitative methods } \\
\text { Quantitative methods }\end{array}$ & $\begin{array}{l}\text { Quantitative methods } \\
\text { Quads }\end{array}$ \\
\hline
\end{tabular}

informed by theories, they can be understood more in the sense of Herbert Blumer's 'sensitizing concepts' (Blumer 1954). They do not give a precise definition of concepts prior to entering the research site, but provide an open, heuristic frame. Interpretive researchers therefore follow an abductive logic of inquiry, expecting these concepts to emerge from the empirical data. The research process is seen as an open, iterative process: as 'an evolving dialogue between fieldwork and framework' (Soss 2006, p. 137).

The difference between positivist and interpretive research is often falsely equated with the debate between qualitative and quantitative methodologies (Yanow 2003b; Yanow and Schwartz-Shea 2006, p. Xviii). However, both apply qualitative and quantitative methods in the collection and analysis of data. The differences between the two research paradigms are illustrated by Table 1.1.

\section{The Choice of Cases}

The contrasting underpinnings of positivist and interpretive research imply that the methods of case selection differ. Looking at 'things-in-context' (Katzenstein 2003, p. 10) means a comparison in interpretive research is based, not on the equivalences between cases, but rather on their singularities (Yanow 2014, p. 132). Therefore, interpretive scholars search for heterogeneity and multiplicity in their choice of cases (Kruse 2014, p. 245; Schwartz-Shea and Yanow 2012, p. 114). This is reflected in the research process. In interpretive research, the choice of cases and access to them is often related (SchwartzShea and Yanow 2012, pp. 69-71). The interest in singularity and contextuality implies that the characteristics of the case are not known to the researcher prior 
to entering the research site, only becoming known during the process of data generation.

For this comparative study, countries were initially selected to represent a homogeneous setting. By their institutional integration in the EU, all of them share the fundamental institutions of democracy, rule of law and market economy. Given their membership in the EU, they are all obligated to fulfill their political commitments toward EU climate and energy policy.

Within the EU, the choice of cases was guided by the search for heterogeneity and diversity. While comparativists often 'defin[e] themselves by their geographical areas of expertise’ (Purdon 2015, p. 3), I aim to cross these boundaries by combining both Western European and CEE countries in this comparative study. They are marked by different trajectories of historical development. The Western European countries belong to the older, more established democracies, whereas the CEE countries belong to the younger, still evolving democracies. Denmark turned democratic with the introduction of a constitutional monarchy in 1849. The development trajectories of the two German states evolved differently after the failed democracy of the Weimar Republic (1919-33) and their separation after World War II. A democracy was established in the Federal Republic of Germany in 1949, whereas it was introduced in the German Democratic Republic only after the democratic transition and German reunification in 1990.

In contrast to the earlier onset of democracy in Denmark and Germany, Estonia and Poland underwent the transition towards democracy with the collapse of communism in the late 1980s/early 1990s. However, Estonia and Poland also exemplify the differences within Central Eastern Europe. While Poland retained its statehood during communism, Estonia regained its independent statehood only in 1991. Therefore, Estonia was confronted with more of a tabula rasa situation and needed to rebuild state institutions in the early 1990s (Randma-Liiv 2005, p. 468; Sootla and Lääne 2013, p. 166; Sootla and Lumi 2008, p. 61; Viks and Randma-Liiv 2005, p. 70).

The different histories of Western European and CEE countries imply differences in the experiences of Europeanization. While Germany was one of the founding members of the European Economic Community in 1957 and Denmark acquired membership of the community in 1973, Estonia and Poland entered the EU with the enlargement of 2004. Accordingly, most literature on environmental policy in Central Eastern Europe discusses the Europeanization of environmental policy during the pre- and post-accession phase. ${ }^{2}$ However, the study of climate policy in Central Eastern Europe remains a research gap, with studies still few and far between (Bokwa 2007; Jankowska 2011; Skjærseth 2016). So far, no one has covered the internal workings of the ministerial administration in climate policy. 
Given these differences in their historical trajectories, one would expect the countries to differ in their approaches to climate policy. As the origins of environmentalism date back earlier in Western European than in CEE countries, support for climate policy is assumed to be stronger in Western European than in CEE countries. This is also expected to shape the evolution of the ministerial administration. The institutionalization of climate policy is assumed to be more firmly established in Western European than in CEE countries.

With the differences between older and younger democracies, one would also expect different policy styles. This is, most importantly, the contrast between the more sedimented, taken for granted political-administrative institutions in the older democracies and the more fluid institutions in the younger democracies. They remain in a process of institution-building where they continue to be challenged and renegotiated. Therefore, practices of interaction and cooperation between state and non-state actors are expected to be more institutionalized in Western European and more contested in CEE countries.

Within Western Europe and Central Eastern Europe, both small and large states are represented in this study. As is frequently the case in the literature, there is no consensus on what constitutes a country's size (Thorhallsson and Wivel 2006, p. 652). Size - and this resonates well with the constructivist ontology adopted by this study - is viewed as a social construction (Hanf and Soetendorp 1998; Thorhallsson 2006). Different indicators such as territory, economic or financial power, political or military power, or population size can be applied to define the size of countries (Hanf and Soetendorp 1998; Panke 2010; Steinmetz and Wivel 2010; Thorhallsson 2006; Thorhallsson and Wivel 2006). Nonetheless, country size remains a relative concept, tied to a spatiotemporal context and defined in relation to other countries (Panke 2010, p. 15; Steinmetz and Wivel 2010; Thorhallsson and Wivel 2006, pp. 654-5). As such, the demarcation of small versus large states remains debatable (Panke 2010, p. 15).

Here, I define the size of countries by population size, which seems useful in relation to my focus on the coordinative discourses of formulating policies. If countries' sizes differ, one would expect differences in their perception of political vulnerability and interdependence, of policy style and state-society relationships. Small states develop a more pronounced sense of vulnerability and interdependence than large states do (Katzenstein 2003, pp. 10-11). Furthermore, a smaller size implies a closeness between agents that might support a policy style with a more mediating code of conduct between state and non-state actors. By contrast, a larger size implies a greater distance between agents. Consequently, a more intervening policy style would be expected.

Accordingly, the countries studied represent different population sizes. With a population of approximately 81.8 million inhabitants, Germany is 
the largest state in Western Europe, and Denmark, with a population of 5.6 million inhabitants, is relatively small. Likewise, Poland, with a population of approximately 38.5 million inhabitants, is the largest state of Central Eastern Europe, and Estonia, with a population of 1.3 inhabitants, is the smallest (OECD 2010). ${ }^{3}$ These differences in the national settings in climate policy are summarized in Table 1.2.

Climate policy evolved to encompass both the causes and the consequences of climate change. Climate mitigation seeks to address the causes of climate change by preventing greenhouse gas (GHG) emissions. It does so in two ways: either by a change in energy production, shifting from fossil fuels to renewable energy sources, or by a change in energy consumption, increasing energy efficiency and energy conservation. Improvements in energy efficiency are often confronted with rebound-effects, so that overall energy consumption remains unaltered or even rises (see for example Gillingham et al. 2016). Therefore, scholars argue that a sole focus on energy efficiency is insufficient. Energy efficiency should be combined with energy conservation in order to achieve absolute energy savings. This is conveyed by the notion of sufficiency.

While the shift in energy production from fossil fuels to renewable energy received ample attention in the political debate, a shift in energy consumption received much less (German Council for Sustainable Development 2012; Hennicke and Hauptstock 2013, p. 35; Ziesing 2013). However, scholars argue that energy conservation is indispensable for a transformation of the energy system, because a comprehensive shift towards renewable energy is deemed feasible only if energy consumption is reduced. The fact that energy efficiency and energy conservation policy have remained under-addressed by politics despite their utmost importance makes them particularly interesting to study. In so doing, I mean to capture the horizontal nature of energy conservation policy, spanning across the boundaries of several policy domains. These include energy, housing and urban development, transport, agricultural, research and education, as well as economic and finance policy.

The search for climate policies that address energy efficiency and energy conservation has revealed differences in the origins of these policies in Western European and CEE countries. While they originated in domestic politics in Denmark and Germany, they grew out of Europeanization in Estonia and Poland. Both Denmark and Germany developed strategies for a long-term transformation of the energy system that encompass energy efficiency and energy conservation policy, namely the Danish Energy Agreement of 2012 and the German Energy Concept of 2010. By contrast, energy efficiency and energy conservation policy were introduced to Central Eastern Europe through Europeanization (Boasson and Wettestad 2013, p. 140). Accordingly, I study the transposition of the EU Energy Services Directive (2006/32/EC) through 


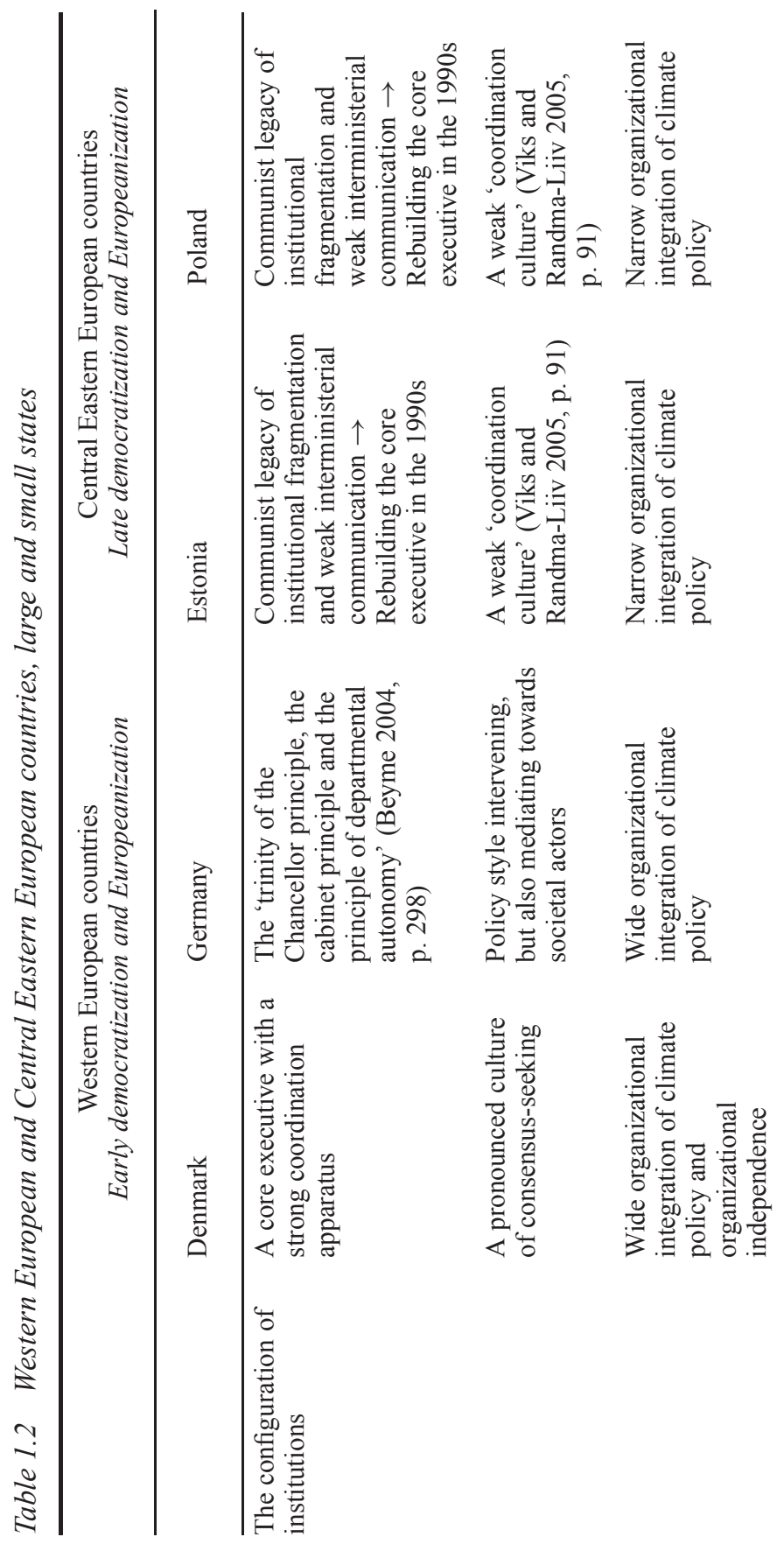




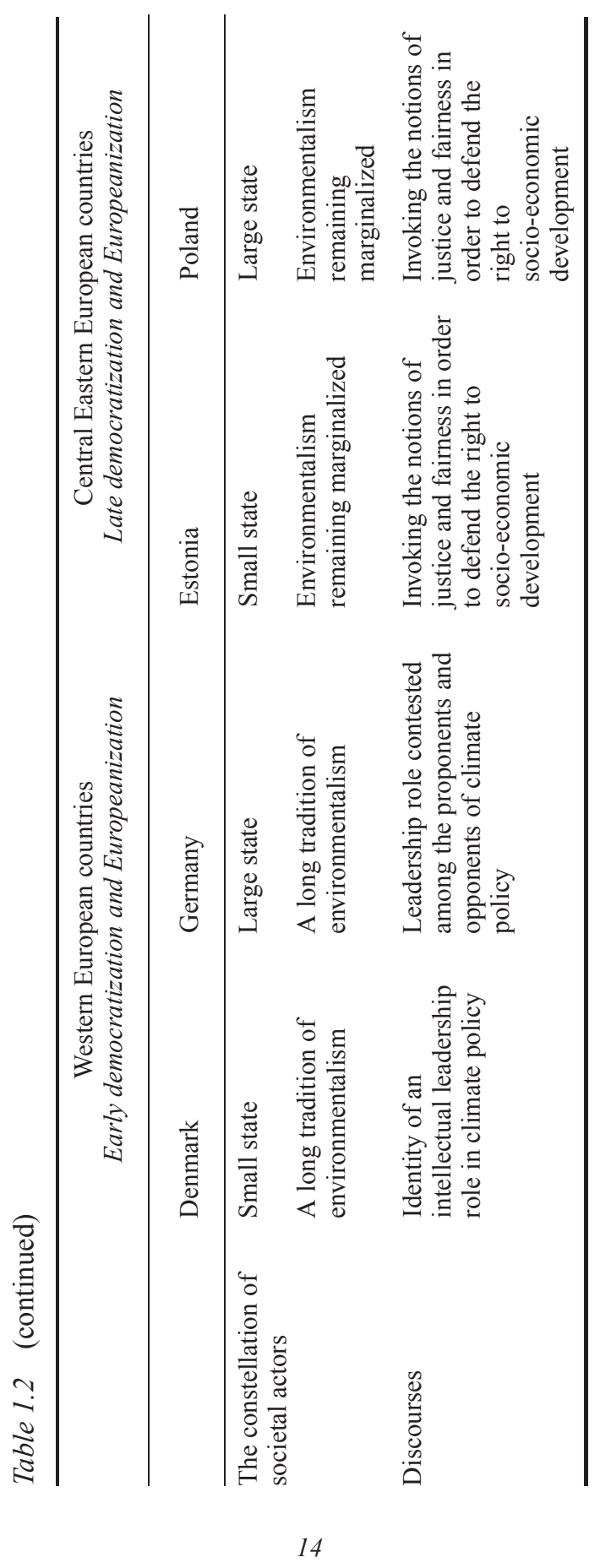


the Estonian Second National Energy Efficiency Action Plan (NEEAP) of 2011 and the Polish Energy Efficiency Act of 2011.

\section{The Methods of Data Generation and Analysis}

The idea of triangulation suggests that a subject should be studied by applying different analytic techniques in order to capture the multi-dimensionality of the research process (Denzin 1970, pp. 300 et seq.; Schwartz-Shea 2006, p. 103; Schwartz-Shea and Yanow 2012, p. 111). Accordingly, three methods of data generation were combined in this study, namely a literature review, document analysis and expert interviews. The existing literature on climate policy and the core executive in each of the four nation states was reviewed. Additionally, policy documents, organizational charts of the national ministries, as well as reports on national climate policy and energy efficiency policy were analyzed. ${ }^{4}$

Overall, 43 expert interviews were conducted: eleven for the study on the Danish Energy Agreement, twelve for the one on the German Energy Concept, eight for the one on the Estonian Second NEEAP and twelve for the one on the Polish Energy Efficiency Act. The entire set of interviews was made anonymous to protect the anonymity requested by the interviewees. ${ }^{5}$ As with the selection of cases, the selection of interviewees sought to represent the heterogeneity of each research site. Therefore, both state and non-state actors were interviewed, including representatives of politics, the national ministerial administration, the business community, science and civil society. Concerning the national ministerial administration, these public officials were chosen so that they would represent ministries from different policy domains.

Based on the idea that reality is socially constructed and can be apprehended only through interpretation, interpretive researchers apply meaning-focused methods to analyze empirical data. These seek to reconstruct human sensemaking (Yanow 2003a, pp. 239-41). One of these methods is the 'integrative basic method' (Kruse 2014, pp. 472-584; Kruse et al. 2011, pp. 46-62; Kruse and Schmieder 2012). It is integrative, as it argues that no one single method of data analysis is sufficient, but that several methods should be combined. Accordingly, this method was applied in analyzing the empirical data.

\subsection{THE OUTLINE OF THE BOOK}

An analytical framework to study the change and continuity of policies is developed in Chapter 2. Defined by the shift towards constructivism, DI seeks to integrate ideas, discourses and institutions. Building on DI, I refine the notion of institutions to depict the role of ministerial administrations in policy formulation. This framework seeks to incorporate the shift from 
macro-institutional to micro-institutional choices implied by the study of these political-administrative institutions in climate policy. The framework is then applied in the interpretive, empirical analysis of policy change.

In Chapters 3, 4, 5 and 6, the four case studies on coordinative discourses in Denmark, Germany, Estonia and Poland analyze the meaning of ideas, discourses and institutions in empirical detail. The Western European countries, Denmark and Germany, experienced the transition to democracy earlier than did the CEE countries, Estonia and Poland. In a similar vein, the Europeanization of the two Western European countries began earlier. Against this backdrop, the origins of climate policy lie in domestic as well as international and EU climate policy. Both Denmark and Germany adopted the idea of a long-term transformation of the energy system until 2050. Denmark did so with the introduction of the Energy Agreement of 2012 and Germany with the introduction of the Energy Concept of 2010. In Chapters 3 and 4, I explore which policy frames and identities shaped how political interests were constructed in Denmark and Germany. While the coordinative discourse on the Danish Energy Agreement was characterized by consensus-seeking on policy change, policy entrepreneurship regarding policy change was more contested in the discourse on the German Energy Concept.

Under communist rule until the late 1980s, Estonia and Poland underwent the transition towards democracy and a market economy far later than the Western European countries did. As with the transition towards democracy, the Europeanization of Estonia and Poland followed later. Compared to Denmark and Germany, the development of climate policy was therefore induced more by internationalization and Europeanization than by domestic politics (Bokwa 2007; Jankowska 2011). However, this is not to argue that internationalization and Europeanization were purely externally driven, top-down processes. They combined top-down with bottom-up processes of policy-making, needing to be translated and negotiated by domestic actors (Börzel and Risse 2007; Kassim 2005, p. 291; Olsen 2003, p. 507).

Energy efficiency policy had traditionally not been on the political agenda of CEE countries. Instead, EU directives introduced energy efficiency policy into Estonian and Polish politics as an element of climate policy (Boasson and Wettestad 2013, p. 140). One example is the transposition of the EU Energy Services Directive (ESD; Directive 2006/32/EC). ${ }^{6}$ The directive had an agenda-setting function for both the Estonian Second National Energy Efficiency Action Plan of 2011 and the Polish Energy Efficiency Act of 2011. In Chapters 5 and 6, I analyze how the EU policy ideas entered domestic institutions in Estonia and Poland. I explore how they were translated, debated and eventually transformed or left unchanged. Having the identity of a small state and a belated modernizer was a guiding policy frame in Estonia. Against this backdrop, policy on energy efficiency lacked political advocacy and the 
coordinative discourse on the Estonian Second NEEAP was dominated by a frame of technocratic compliance with the ESD. In contrast, the Ministry of Economy in Poland regarded energy efficiency policy as a form of ecological modernization. It therefore acted as a policy entrepreneur, portraying the introduction of the Polish Energy Efficiency Act as an opportunity for policy innovation.

Chapter 7, section 7.1 compares the empirical insights gained from the four cases. It discusses the similarities and differences between the four empirical examples of policy change. These are expressed by the identities in climate policy, the policy styles and discursive practices, the politics of expertise, the ambiguity of organizational identities, the dynamics of politicization and technocratization, and the manner of addressing the politics of policy change, namely the question of reinterpreting policy ideals and redefining political interests. In section 7.2, I turn to the implications of the comparative analysis for the empirical study of climate policy, the development of neo-institutional theory and political practice. The comparative analysis addresses a gap in empirical research regarding the role of the ministerial administration in climate policy and climate policy in Central Eastern Europe. It contributes to neo-institutional theory by bringing the state back into the study of climate policy and refines the notion of institutions as proposed by DI by incorporating the ministerial administrations as micro-institutions. This offers new insights into the conception of policy styles. The chapter ends with the lessons drawn for political practice. Section 7.3 then addresses the boundaries of the comparative study and delineates questions for future research.

\section{NOTES}

1. See for example Béland and Cox 2011; Bevir and Rhodes 2003; Bevir and Rhodes 2016; Campbell 2004; Hay 2011; Hogan and Howlett 2015.

2. Among others see Andonova 2004; Auer 2005; Bochniarz and Cohen 2006; Carmin and VanDeveer 2005; Galbreath 2010; Guttenbrunner 2009; Pavlínek and Pickles 2004; Raudsepp et al. 2009; Streimikiene et al. 2006; Streimikiene and Mikalauskiene 2007.

3. These data represent the population sizes in 2010 .

4. A list of the documents that were analyzed for each case study can be provided upon request.

5. A list of these expert interviews is provided in Appendix I.

6. Directive 2006/32/EC of the European Parliament and of the Council of 5 April 2006 on energy end-use efficiency and energy services. 